\title{
A NeW TyPe OF COMPOSITE TURQUOISE
}

\author{
Gagan Choudhary
}

Several conspicuously colored specimens marketed as dyed and/or stabilized turquoise were recently examined. They were purple to purple-pink, yellow-green, and blue, in veined and unveined varieties. Testing revealed that all the specimens were composites of turquoise pieces bonded together; the purple to purple-pink and yellow-green samples were bonded with a colored polymer, and the blue ones had a colorless polymer. This article presents the gemological properties and EDXRF and FTIR analyses of this material, along with its reaction to the solvents acetone and methylene chloride.

$\mathrm{T}$ urquoise, best known for its splendid blue color, has been used for adornment since antiquity. Chemically a hydrous copper aluminium phosphate, it has a cryptocrystalline structure composed of fine, randomly oriented groups of triclinic crystals (Webster, 1994). This cryptocrystalline structure gives rise to the gem's porosity, making it susceptible to body oils, ordinary solvents, or even dirt, which can alter its color. For decades, turquoise has been impregnated with wax, plastics, or polymers-a process known as stabilization, which enhances not only the material's durability but also its color and surface luster (Nassau, 1994). Another established treatment is the dyeing of pale-colored turquoise to give it a rich blue color (see, e.g., Kammerling, 1994). In recent years, a few other proprietary treatments have been developed for turquoise. The most prominent is Zachery treatment, which decreases the porosity of the original material, so it takes a better polish; the blue color may

See end of article for About the Author and Acknowledgments. Gems \& GemOlogy, Vol. 46, No. 2, pp. 106-113.

(C) 2010 Gemological Institute of America also be enhanced through an additional step in the process (Fritsch et al., 1999). Yet another form of treatment seen on the market, developed by Eljen Stones, involves polymer impregnation (Owens and Eaton-Magaña, 2009).

Recently, this author had the opportunity to study a group of distinctively colored purple and yellow-green turquoise samples, as well as blue turquoise (figure 1). When first seen at the Jaipur Jewellery Show in December 2008, their market availability was limited. Since the beginning of 2010, however, the Gem Testing Laboratory of Jaipur has received an increasing number of these treated turquoises for identification. While previous studies have reported on dyed and impregnated blue turquoise (Kammerling, 1994) and green turquoise produced by immersion in mineral oil (Koivula et al., 1992), these specimens were quite different. Upon inquiry, the supplier said they were pieces of natural turquoise that had been dyed and bonded together, though he knew little about the process involved. He did divulge that this material is being manufactured in the United States. We subsequently received a variety of rough and cut samples for study, and this article reports on the properties of these samples, some of which appear similar to those seen by McClure and Owens (2010) in the GIA Laboratory.

\section{MATERIALS AND METHODS}

The 21 samples were purple to purple-pink, yellow-green, and blue. Fifteen were fashioned as cabochons weighing 8.10-21.83 ct (again, see figure 1), and the other six were rough pieces with a total weight of $47.90 \mathrm{~g}$ (figure 2). The samples were divided into seven groups of three each on the basis of bodycolor, the presence/absence of veining, and whether they were rough or fashioned. The groups were: unveined purple to purple-pink rough, unveined yellow-green rough, unveined and veined purple to purplepink cabochons (two groups), unveined and veined yellowgreen cabochons (two groups), and veined blue cabochons.

Standard gemological tests were performed on all the cabochons to determine their RI, hydrostatic SG, and UV fluorescence. Absorption spectra were observed with a desk-model GIA Prism 1000 spectroscope. A binocular gemological microscope with fiber-optic lighting in addi- 


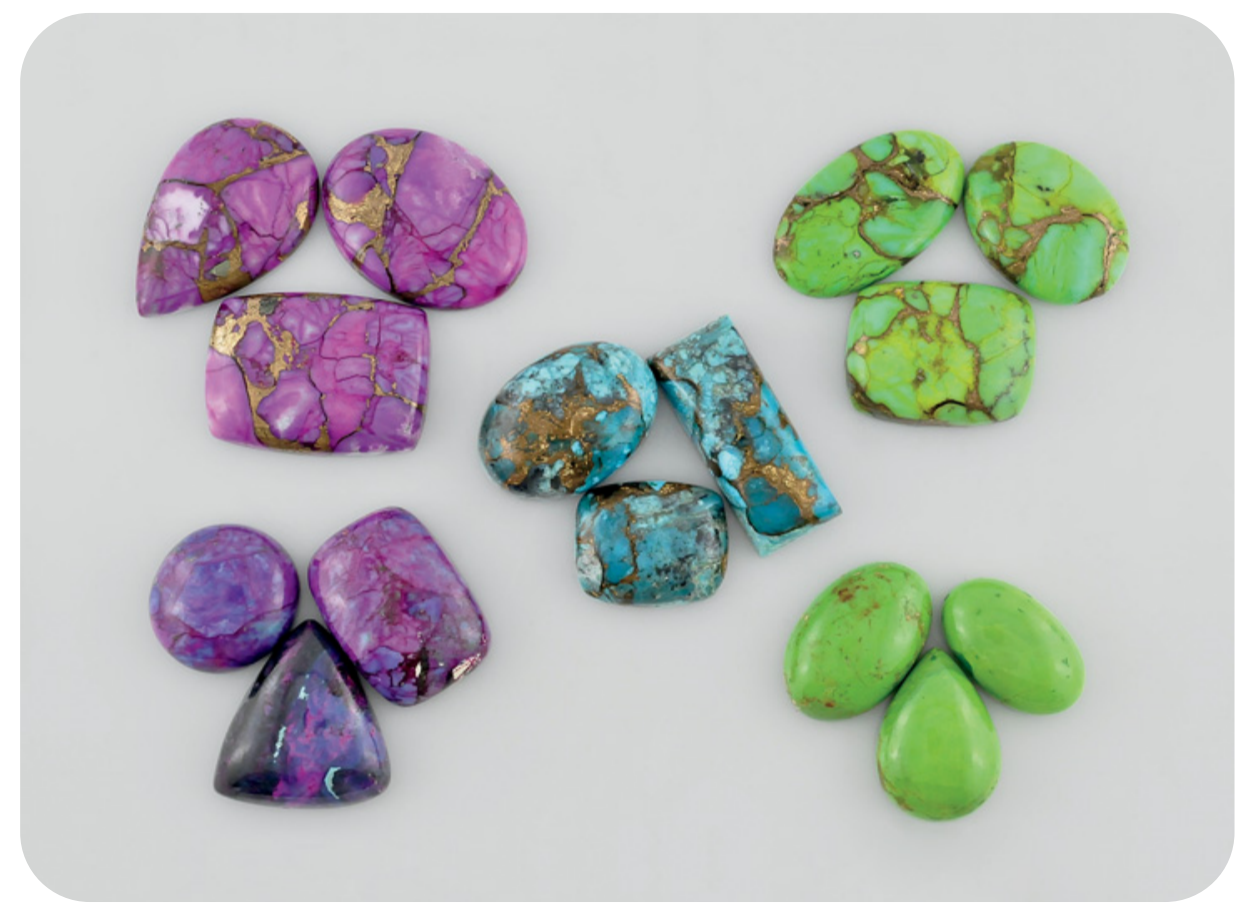

Figure 1. The 15 treated turquoise cabochons examined for this study are divided here into veined and unveined (or minimally veined) varieties that are purple to purple-pink (11.82-21.83 ct), yellowgreen $(8.10-18.12 \mathrm{ct})$, and blue $(9.78-20.10 \mathrm{ct})$. Photo by G. Choudhary.

tion to the overhead white light was used to examine the structure and surface features. A needle was used to probe various parts of both the rough and cut samples.

We also noted the reaction of two samples to solvents such as acetone and methylene chloride. Acetone is commonly used to check for the presence of dye in gem materials, and methylene chloride is an excellent solvent for polymers. We brushed an acetone-dipped cotton swab on an unveined yellow-green cabochon and soaked a piece from the same sample in acetone for 48 hours to observe the changes; the rest of this sample was retained for comparison. We also soaked one veined yellow-green cabochon in

Figure 2. These rough samples of treated turquoise (5.75-10.11 g) show unusual colors and a polymer-like luster. Concentrations of colored polymer are visible as the yellow-brown area on the right corner of the upper yellow-green sample, and the red areas on the bottom purple to purple-pink samples. Photo by G. Choudhary.

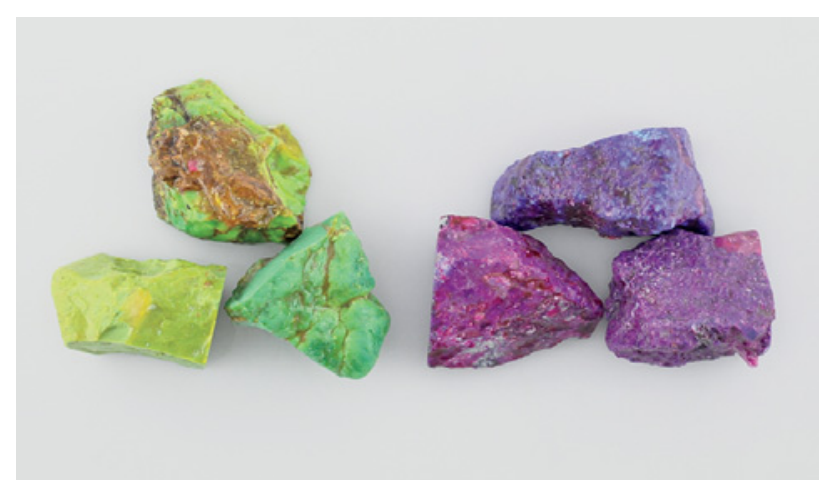

methylene chloride for 48 hours and noted the reaction at occasional intervals. For comparison, a natural untreated turquoise was immersed in methylene chloride for the same duration.

We performed qualitative chemical analyses on all 15 cabochons with energy-dispersive X-ray fluorescence (EDXRF) spectroscopy, using a PANalytical Minipal 2 instrument operated with a voltage of $15 \mathrm{kV}$ and current of $0.016 \mathrm{~mA}$.

Infrared spectra were recorded on all cabochons in the $6000-400 \mathrm{~cm}^{-1}$ range with a Shimadzu IR Prestige 21 Fourier-transform infrared (FTIR) spectrometer operating at room temperature in diffuse reflectance mode, using a standard resolution of $4 \mathrm{~cm}^{-1}$ and 50 scans per sample. The results were then converted to absorbance using the spectrometer software.

\section{RESULTS AND DISCUSSION}

Visual Characteristics. As mentioned earlier, the turquoise samples were purple to purple-pink, yellowgreen, and blue (again, see figures 1 and 2). The purple to purple-pink range is not associated with turquoise and indicates artificial coloration. The veins present contained metallic gold-colored "matrix" that generally appeared much brighter than that seen in natural turquoise. Except for the yellow-green unveined variety, the specimens displayed an uneven body color. The purple to purple-pink and veined yellow-green specimens displayed some distinct blue patches representing the original turquoise before treatment. These features were indicative of dyeing. The blue samples did not exhibit any obvious signs of dyeing and had a more natural appearance, though the thick- 

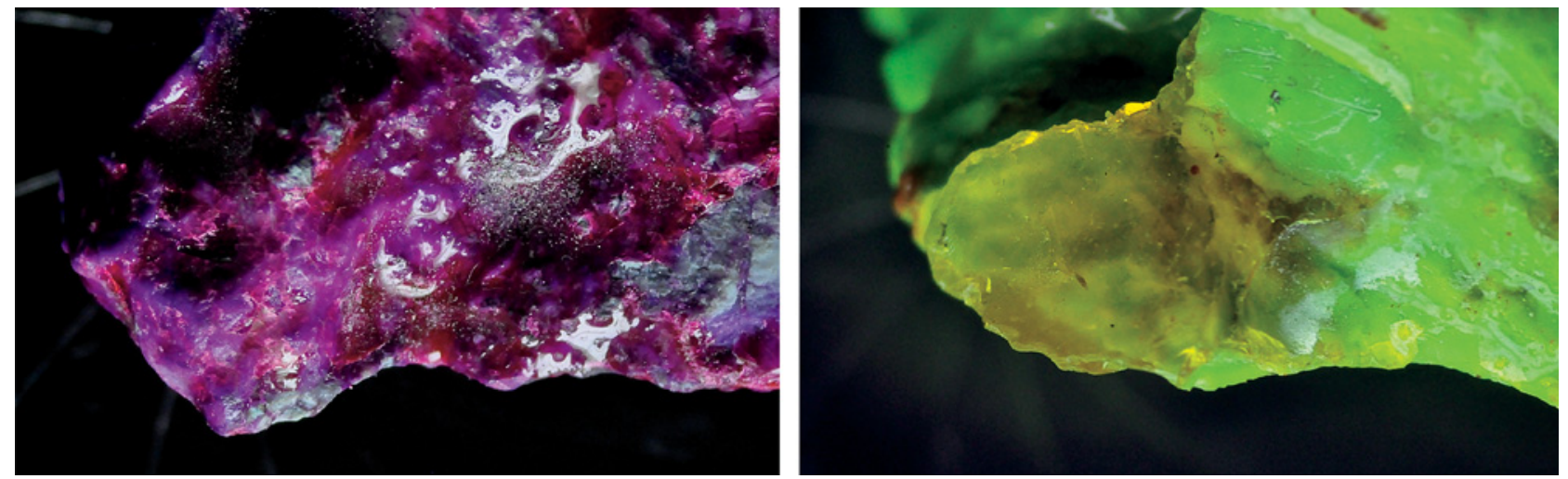

Figure 3. Concentrations of color appear on the surface of these rough samples of purple to purple-pink and yellow-green turquoise. The IR spectrum of the transparent yellow-brown area in the image on the right matched that of a polymer and some of the peaks recorded in the polished specimens. Photomicrographs by G. Choudhary; magnified 30x.

ness of the veins raised suspicions about their origin.

The rough purple to purple-pink specimens displayed obvious reddish concentrations on their surface (figure 3, left) and were easily identified as artificially colored; they also displayed a dull to waxy and oily luster, which is associated with polymers and resins. The color of the yellow-green rough was more even, with only one specimen displaying an obvious concentration of a transparent yellow-brown substance (figure 3, right). Similar concentrations of a transparent colored material were visible on the purple to purple-pink samples, too. The other two yellow-green pieces were fairly evenly colored, though they also displayed the luster associated with polymers and resins.

TABLE 1. Properties of natural turquoise and dyed composite turquoise.

\begin{tabular}{|c|c|c|c|c|}
\hline \multirow{2}{*}{$\begin{array}{l}\text { Property } \\
\text { Color }\end{array}$} & \multirow{2}{*}{$\begin{array}{l}\text { Natural turquoise } \\
\text { (Webster [1994] unless } \\
\text { noted otherwise) }\end{array}$} & \multicolumn{3}{|c|}{$\begin{array}{l}\text { Dyed composite turquoise } \\
\text { (this study) }\end{array}$} \\
\hline & & $\begin{array}{l}\text { Purple to purple-pink } \\
\text { (veined and unveined) }\end{array}$ & $\begin{array}{l}\text { Yellow-green } \\
\text { (veined and unveined) }\end{array}$ & Blue (veined) \\
\hline Luster & Waxy & & Dull to waxy & \\
\hline $\mathrm{Rl}$ & 1.62 (mean) & 1.61 (spot) & $\begin{array}{l}1.61 \text { (spot) } \\
1.54 \text { for two samples, } \\
\text { probably due to polymers }\end{array}$ & 1.61 (spot) \\
\hline SG & $2.60-2.90$ & $2.23-2.60$ & $2.03-2.55$ & $2.44-2.49$ \\
\hline \multicolumn{5}{|l|}{ UV fluorescence } \\
\hline Long-wave & $\begin{array}{l}\text { Greenish yellow to } \\
\text { bright blue }\end{array}$ & Strong patchy orange-red & $\begin{array}{l}\text { Weak patchy blue; } \\
\text { mostly inert }\end{array}$ & Strong patchy blue \\
\hline Short-wave & Inert & $\begin{array}{l}\text { Moderate patchy orange- } \\
\text { red }\end{array}$ & Inert & Moderate patchy blue \\
\hline Spectroscope spectrum & $\begin{array}{l}\text { Vague band at } 460 \mathrm{~nm} \text {, } \\
\text { fine lines at } 420 \text { and } 432 \\
\mathrm{~nm}\end{array}$ & $\begin{array}{l}\text { Bands in the green and } \\
\text { yellow region at } \sim 510,540, \\
\text { and } 580 \mathrm{~nm}\end{array}$ & $\begin{array}{l}\text { Diffused absorption in the } \\
\text { blue region at } 450-490 \mathrm{~nm}\end{array}$ & No absorption features \\
\hline Microscopic features & $\begin{array}{l}\text { White clouds, crystals of } \\
\text { various mineral inclusions } \\
\text { (Fritz et al., 2007; Koivula } \\
\text { and McClure, 2009) }\end{array}$ & \multicolumn{3}{|c|}{$\begin{array}{c}\text { Concentrations of red and yellow, patches of polymer, veins of "golden" } \\
\text { material with or without brassy yellow fragments. }\end{array}$} \\
\hline EDXRF analysis & $\mathrm{CuAl}_{6}\left(\mathrm{PO}_{4}\right)_{4}(\mathrm{OH})_{8} \cdot 4 \mathrm{H}_{2} \mathrm{O}+\mathrm{Fe}$ & \multirow{2}{*}{\multicolumn{3}{|c|}{$\begin{array}{l}\text { Al, P, Fe, and Cu (and Zn in veined samples) } \\
\text { Peaks related to polymers in the } 3200-2800 \text { and } 2000-1000 \mathrm{~cm}^{-1} \text { regions }\end{array}$}} \\
\hline FTIR analysis & $\begin{array}{l}\text { Peaks at } 1125,1050 \text {, and } \\
1000 \mathrm{~cm}^{-1} \text {; band at } 1746 \\
\mathrm{~cm}^{-1}(\text { e.g., Moe et al., 2005) }\end{array}$ & & & \\
\hline Reaction to metal probe & None & \multirow{2}{*}{\multicolumn{3}{|c|}{$\begin{array}{l}\text { Indentations due to lower hardness of polymer } \\
\text { Loss of the impregnated color when soaked in acetone; veined sample } \\
\text { completely disintegrated into fragments when soaked in methylene chloride }\end{array}$}} \\
\hline Reaction to solvents & $\begin{array}{l}\text { Blue color turns green after } \\
\text { contact with body oils and } \\
\text { the like }\end{array}$ & & & \\
\hline
\end{tabular}


Gemological Properties. The gemological properties of the studied turquoise are described below and summarized in table 1 .

Refractive Index. Except for two yellow-green specimens, all samples (whether veined or unveined) yielded a spot RI of approximately 1.61 with a moderate birefringence blink. This value is consistent with those reported for natural turquoise. Two anomalous yellow-green samples-one veined and one unveined — displayed spot RIs of $\sim 1.54$, and no birefringence was visible. This lower RI value could have been due to a thicker layer of polymer on the surface or to a larger percentage of polymer in the structure of the turquoise.

\section{NEED TO KNOW}

- Purple-pink, yellow-green, and blue composite turquoise has been marketed since late 2008.

- The pieces of turquoise are bonded together using a polymer (colored to produce the purplepink and yellow-green varieties).

- Some of the turquoise has veins or "matrix" material composed of a gold-colored polymer with fragments resembling pyrite/marcasite.

- The composite turquoise can be identified by its microscopic appearance, UV fluorescence, spectroscope spectrum, and FTIR features.

Specific Gravity. The samples displayed a wide range of SG values, from 2.03 to 2.60. Webster (1994) and O'Donoghue (2006) reported SGs of 2.60-2.91 for untreated turquoise, depending on its porosity. Although porosity can cause fluctuations in SG readings, we did not observe such fluctuations in our samples, as expected for polymertreated material. Only one of the 15 cut samples had an SG of 2.60, while the rest were below that. These lower values are consistent with the presence of a polymer. No consistent variations in SG were seen across colors or between veined and unveined samples.

UV Fluorescence. The samples showed distinct fluorescence reactions to long-wave UV radiation-which varied according to their bodycolor (figure 4)-and had weaker reactions or were inert to short-wave UV. The purple to purple-pink turquoise fluoresced a bright patchy orangered to long-wave UV. The blue turquoise displayed a strong patchy blue fluorescence, while the yellow-green samples were mainly inert, with only the residual blue areas fluorescing blue. In all the samples, the veined areas were inert. Webster (1994) also reported greenish yellow to bright blue fluorescence to long-wave UV, and the patchy blue in these specimens likely corresponded to residual areas of natural blue turquoise.

Spectroscope Spectrum. The purple to purple-pink specimens displayed a series of three bands in the green and yellow regions at $\sim 510,540$, and $580 \mathrm{~nm}$; the intensity of the latter two bands was stronger than that of the $510 \mathrm{~nm}$ band. In the yellow-green samples, a broad diffused absorption was seen in the blue region between 450 and $490 \mathrm{~nm}$. No absorption features were seen in the blue turquoise.

Magnification. Microscopic examination of the samples revealed the following features.

- Luster: Polymer-filled areas and cavities displayed a distinctly dull to waxy and oily luster compared to the turquoise areas (see figures 3 and 5). The areas of accumulated polymer in the cabochons also appeared to be indented.

- Color Concentrations: Most of the samples showed distinct color concentrations that varied according to bodycolor. The yellow-green turquoise displayed some yellow concentrations that formed swirly patches or followed veins (figure 6, left). The yellow appeared to be superimposed on the blue base of natural turquoise pieces, resulting in an overall green coloration. A few cavities in the cabochons were filled with the same yellow material. Similarly, the purple to purple-pink samples also displayed color concentrations (figure 6, right),

Figure 4. Here, the samples are shown in the same orientation as figure 1 during exposure to long-wave UV radiation. Their reactions varied with color. Note the striking orange-red fluorescence of the purple to purple-pink samples. The blue turquoise displayed a patchy blue fluorescence, while the yellow-green samples were inert with residual blue areas fluorescing blue. Photo by G. Choudhary.

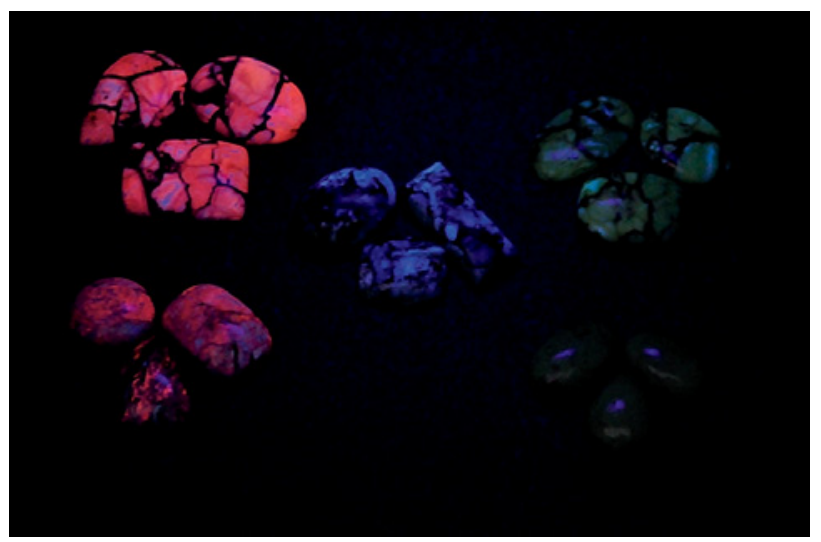




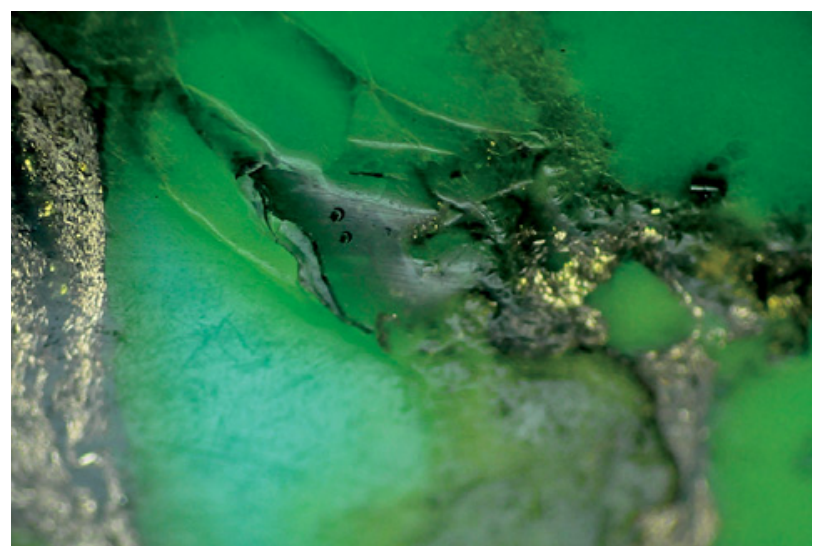

Figure 5. Polymer-filled areas and cavities in the turquoise appear to be indented and display a dullto-waxy luster. Photomicrograph by G. Choudhary; magnified $45 \times$.

with areas of red present as patches and in veins and cavities. The color concentrations indicated that the yellow-green and purple turquoise varieties had been dyed, and the presence of deep ridges suggested that these samples-veined and unveined-were composites, consisting of individual pieces of turquoise held together by a colored polymer matrix. Also, the yellowgreen sample that was broken prior to soaking in acetone displayed uniform color in the broken areas, indicating that the dye penetrated completely through the stone. The blue samples did not display any color concentrations, which indicated that they were not dyed; the polymer seen on the surface and in the ridges of those samples was colorless.

- Veins: Natural turquoise usually contains matrix formed by brown-to-black veins of limonite (O'Donoghue, 2006). Grains of pyrite/marcasite may also be present, often along the veins or in the matrix (Fritz et al., 2007). In the study samples, the veins consisted predominantly of a brighter "golden" yellow substance that was colored by fine flakes (figure 7). Commonly present in this substance were fragments with a duller brassy appearance. It appeared that pieces of pyrite/marcasite were embedded in a gold-colored polymer during the production of the artificial veins.
- Reaction to a Metal Probe: When probed with a needle to check for the presence of a polymer, both rough and cut samples readily indented. This test has been performed for many years to identify impregnated turquoise (see, e.g., Kammerling, 1994). The needle made indentations in the "golden" yellow veins or "matrix" as well (figure 7, right), revealing the softness expected for a polymer; the duller brassy fragments were not affected by the metal probe.

Reaction to Solvents. A cotton swab dipped in acetone and rubbed on the surface of one unveined yellow-green sample did not result in any loss of color. A piece of an unveined yellow-green sample that was soaked in acetone for 48 hours displayed an apparent loss of color and became patchy (figure 8 , right sample), while the acetone became pale yellow-green. The soaked sample also had a significantly duller luster and showed a pimply surface and numerous cracks (figure 9).

A veined yellow-green sample that was soaked in methylene chloride showed significant changes after $\sim 3$ hours (figure 10). The metallic-appearing substance that formed the veins started to leave the specimen and showed a flaky appearance. After $\sim 18$ hours, individual pieces of the specimen were distinctly visible in the liquid, and the liquid turned slightly greenish yellow. After $\sim 48$ hours, the specimen had completely disintegrated into small grains and fragments, similar to the effect described by Rockwell (2008). The surface of the beaker in which the specimen was immersed also showed distinct color concentrations released from the sample after the methylene chloride evaporated. In contrast, a piece of natural untreated turquoise that was immersed in methylene chloride for comparison was unaffected.

The reaction in the methylene chloride bath and the similar structural features (e.g., the presence of deep ridges) seen in all samples confirmed they are composites and not merely dyed and/or impregnated. At this stage, we do not know what impact common household cleaning products and other solvents might have on the polymer(s) used in these composites.

EDXRF Analysis. Qualitative EDXRF analysis of all cabochons (veined and unveined) revealed the presence of $\mathrm{Al}, \mathrm{P}$,
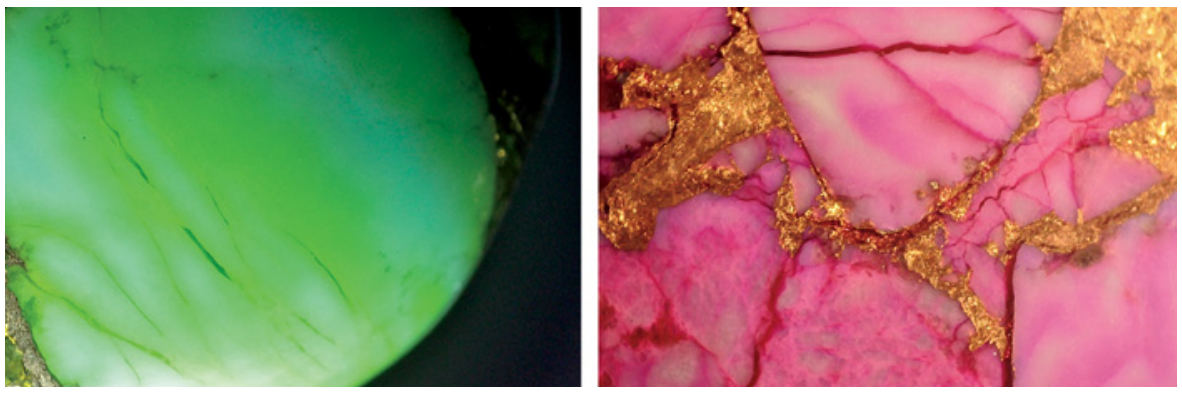

Figure 6. Concentrations of yellow (left, magnified 30x) and red (right, $45 \times$ ) reveal the presence of an artificial dye. On the left, the yellow color superimposed on the blue base gives rise to a yellowish green bodycolor. Also note the deep ridges filled with color. Photomicrographs by G. Choudhary. 

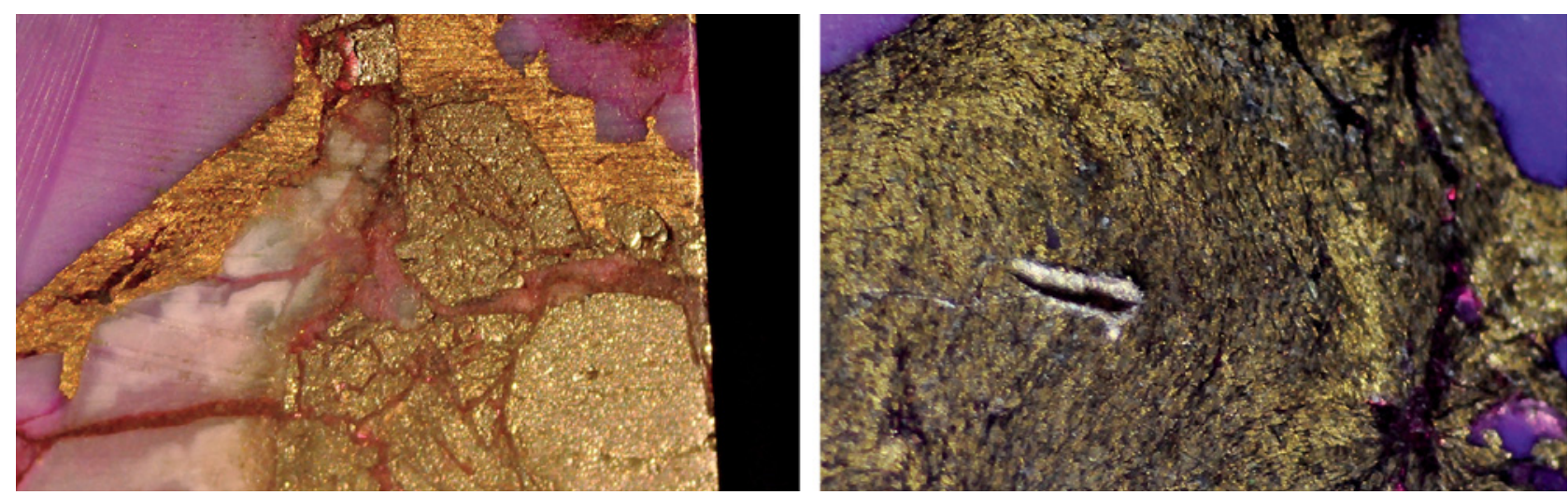

Figure 7. The veins or "matrix" in the turquoise appear to consist of a bright "golden" yellow material containing fragments with a brassy color resembling pyrite/marcasite (left). The photo on the right shows the tiny gold-colored flakes that color the matrix material; the gash made by the needle probe indicates its softness. Photomicrographs by G. Choudhary; magnified 30× (left) and 45× (right).

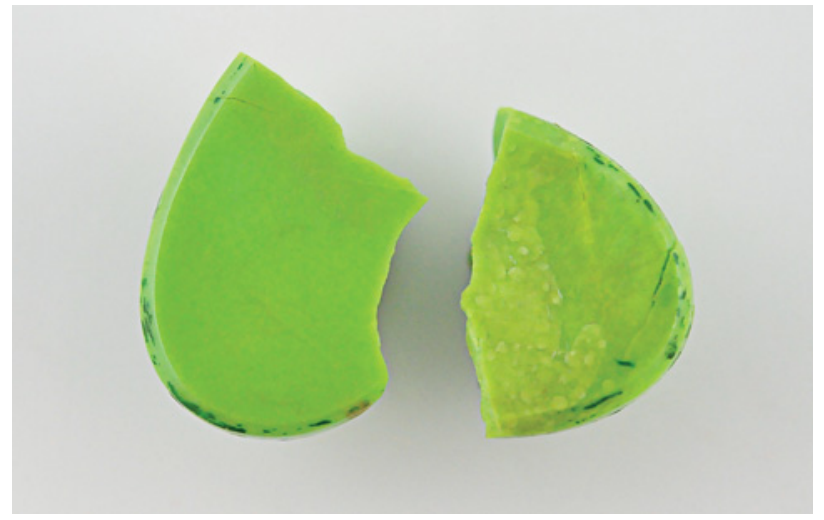

Figure 8. An 8.90 ct unveined yellow-green turquoise was broken and the portion on the right immersed in acetone for 48 hours, resulting in a duller luster and patchy loss of color. Photo by G. Choudhary.

$\mathrm{Fe}$, and $\mathrm{Cu}$, consistent with the chemical composition of turquoise. No potassium peak was present, which ruled out the possibility of Zachery treatment (Fritsch et al., 1999). Yet the veined samples displayed an additional $\mathrm{Zn}$ peak. EDXRF analysis of the "golden" metallic-looking material that flaked off after soaking a veined sample in methylene chloride (discussed above) confirmed the presence of $\mathrm{Zn}$ as well as $\mathrm{Cu}$.

FTIR Analysis. FTIR spectroscopy has long been the most powerful tool in the nondestructive identification of polymer-treated stones (e.g., Fritsch et al., 1992). In this study, FTIR analysis of all cabochons (veined as well as unveined) displayed fairly consistent absorption features in the $3200-2800 \mathrm{~cm}^{-1}$ and $2000-1000 \mathrm{~cm}^{-1}$ ranges.

In the $3200-2800 \mathrm{~cm}^{-1}$ region, distinct absorption bands were visible at $\sim 3125$ (consisting of twin humps), 2970, and $2875 \mathrm{~cm}^{-1}$ (figure 11, left); the latter two are associated with polymers (Fritsch et al., 1992; Moe et al., 2005). However, no peak was detected near $3035 \mathrm{~cm}^{-1}$, which suggests the absence of Opticon or other resins (Johnson et al., 1999).

The $2000-1000 \mathrm{~cm}^{-1}$ region (figure 11 , right) displayed major absorption bands at $\sim 1750,1595,1487,1270$, and $1060 \mathrm{~cm}^{-1}$, in addition to some fine absorption features at 1896, 1857, 1825, 1380, and $1193 \mathrm{~cm}^{-1}$. Moe et al. (2005) stated that peaks at $\sim 1125,1050$, and $1000 \mathrm{~cm}^{-1}$ are associated with natural (not synthetic) turquoise. In the
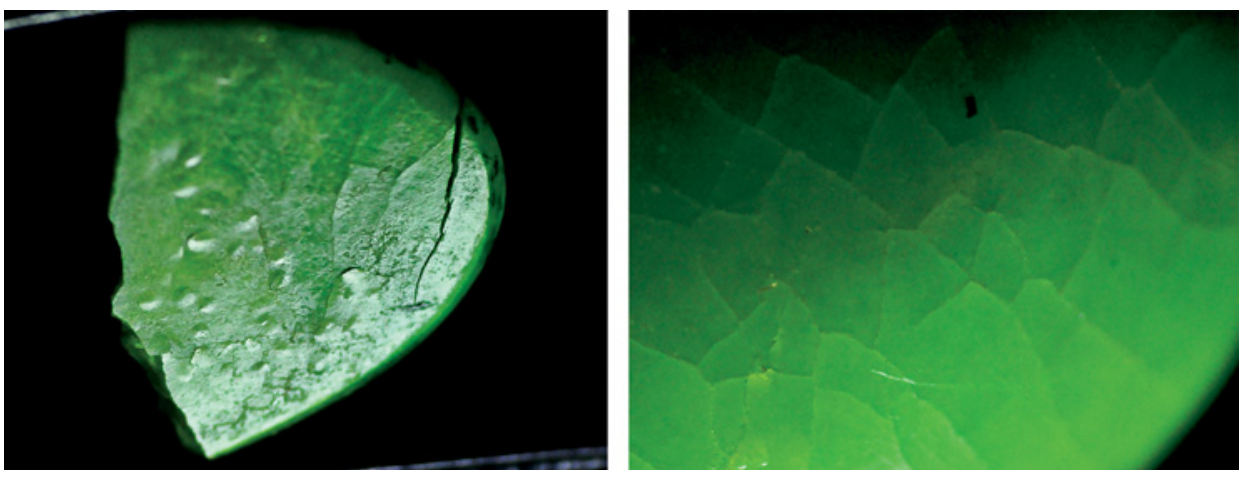

Figure 9. The immersed portion of the sample in figure 8 displayed a pimply surface (left, magnified 30x) and numerous cracks (right, 45×). Photomicrographs by $G$. Choudhary. 

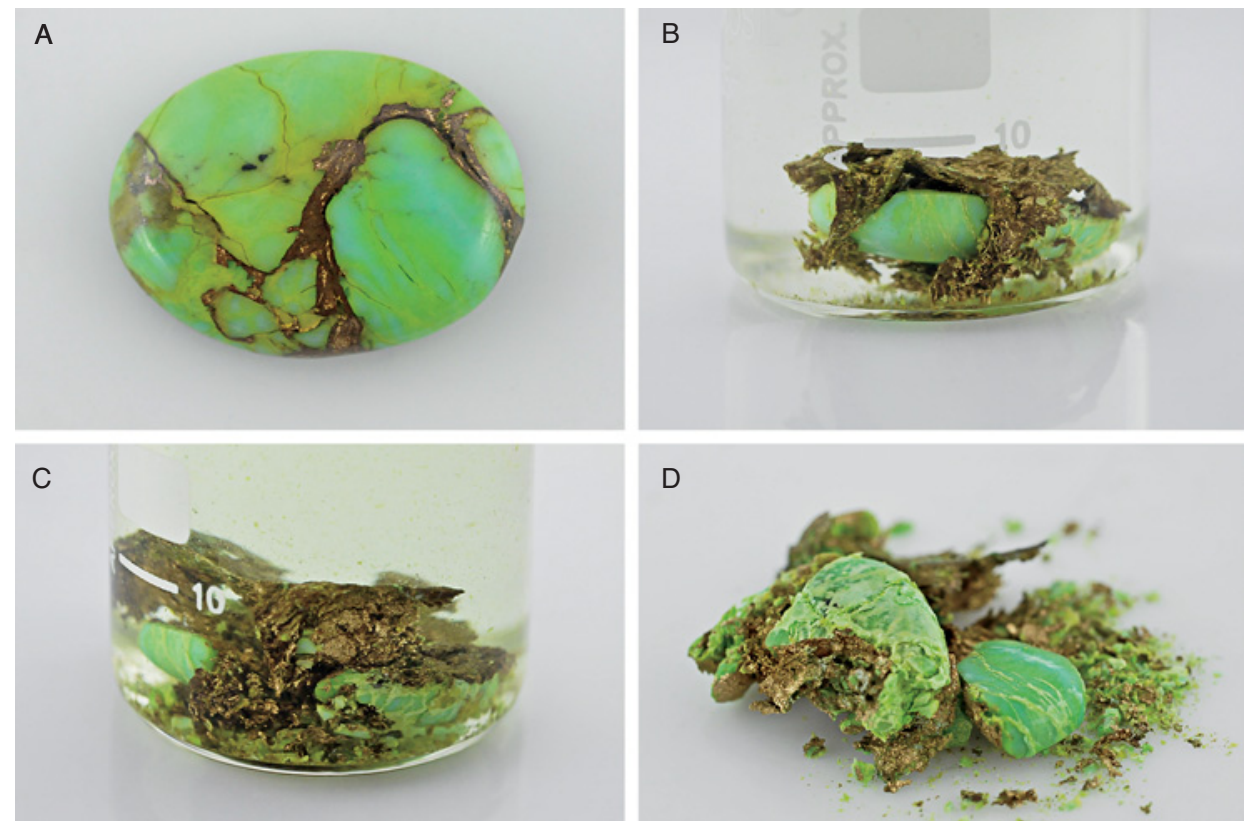

Figure 10. A veined 11.29 ct yellow-green sample (A) was soaked in methylene chloride. After $~ 3$ hours, the metallicappearing substance in the veins started to leave the specimen (B). After 18 hours, separate pieces of the specimen were distinctly visible (C). After 48 hours, the specimen completely disintegrated $(D)$. Also note in $C$ the color of the liquid, which turned slightly greenish yellow. Photos by G. Choudhary. present samples, however, the peak at $\sim 1050 \mathrm{~cm}^{-1}$ varied from 1075 to $1045 \mathrm{~cm}^{-1}$, there was no $1125 \mathrm{~cm}^{-1}$ peak, and the peak at $1000 \mathrm{~cm}^{-1}$ was present at around $1015 \mathrm{~cm}^{-1}$ (not shown in figure 11). The bands at $\sim 1750$ and $1595 \mathrm{~cm}^{-1}$ are related to polymers, in which the former is assigned to $\mathrm{C}=\mathrm{O}$ stretching ( 1744) and the latter to $\mathrm{CH}_{3}$ bending $\left(\sim 1600 \mathrm{~cm}^{-1}\right.$; Moe et al., 2007). The peak at $\sim 1000 \mathrm{~cm}^{-1}$ is associated with the styrene phenyl ring, but it does not play an important role in the identification of a polymer, because it is also present in natural turquoise (Moe et al., 2005). The cause of the $\sim 1487$ and $\sim 1270 \mathrm{~cm}^{-1}$ peaks is not known; the position of the latter varied from 1270 to $1240 \mathrm{~cm}^{-1}$.
The FTIR spectrum of a yellow chip taken from the surface of a yellow-green sample in figure 3 displayed all the polymer-related peaks mentioned above. This confirms the presence of a polymer-like material within or on the surface of these turquoises. The spectrum of this chip displayed an additional peak at $\sim 1270-1240 \mathrm{~cm}^{-1}$, and the cause of this peak in the turquoise could have been the polymer.

\section{CONCLUSION}

These composites, typically marketed as "stabilized" turquoise, consist of small fragments of turquoise bond-

Figure 11. The infrared spectrum recorded for all cabochons in the 3200-2800 $\mathrm{cm}^{-1}$ region (left) displays distinct absorption bands at 3125, 2970, and $2875 \mathrm{~cm}^{-1}$; the latter two are associated with polymers. The spectrum in the 2000-1000 $\mathrm{cm}^{-1}$ region (right) also displays some polymer-related peaks, at 1750 , 1595, and $1270 \mathrm{~cm}^{-1}$, as well as the $1060 \mathrm{~cm}^{-1}$ peak associated with natural (not synthetic) turquoise.
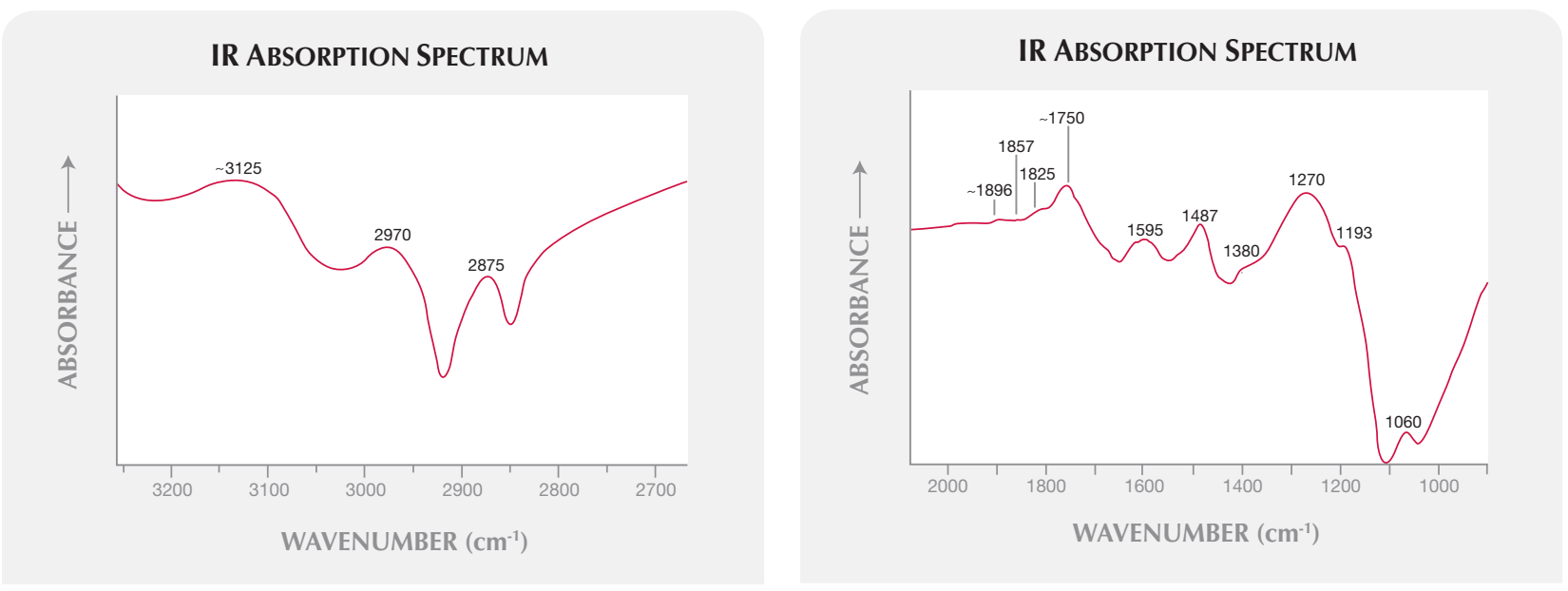
ed together with a colored polymer (in the case of the purple to purple-pink and yellow-green samples) or a colorless polymer (blue samples). Furthermore, veined samples contain interstitial areas formed of a gold-colored polymer containing fragments that resemble pyrite/marcasite.

These materials provide a wider range of turquoise colors for the consumer. Identifying them should not pose any problem. Careful microscopic examination along with UV fluorescence, spectroscope spectrum, and FTIR analysis should easily establish their dyed/composite nature.

\section{REFERENCES}

Fritsch E., McClure S., Ostrooumov M., Andres Y., Moses T. Koivula J.I., Kammerling R.C. (1999) The identification of Zachery-treated turquoise. Ge G, Vol. 35, No. 1, pp. 4-16.

Fritz E.A., Koivula J.I., Laurs B.M. (2007) Gem News International: Turquoise from Nacozari, Sonora, Mexico. Ge $G$ Vol. 43, No. 1, pp. 75-77.

Johnson M.L., Elen S., Muhlmeister S. (1999) On the identification of various emerald filler substances. $G \uplus G$, Vol. 35, No. 2, pp. 82-107.

Kammerling R.C. (1994) Gem Trade Lab Notes: Turquoise, dyed and impregnated. $G \uplus G$, Vol. 30, No. 2, pp. 120-121.

Koivula J.I., McClure S. (2009) Lab Notes: Uranium mineral as inclusions in turquoise. $G \uplus G$, Vol. 45, No. 4, pp. 294-295.

Koivula J.I., Kammerling R.C., Fritsch E. (1992) Gem News: Modern-day turquoise oiling. $G \uplus G$, Vol. 28, No. 2, p. 137.

McClure S., Owens P. (2010) Lab Notes: Treated green turquoise. $G \uplus G$, Vol. 46, No. 1, pp. 56-57.

\section{ABOUT THE AUTHOR}

Mr. Choudhary (gtl@gjepcindia.com) is assistant director of the Gem Testing Laboratory, Jaipur, India.

\section{ACKNOWLEDGMENTS}

The author thanks Dolphin Gems of Jaipur for providing the study samples, and Tomas Burke for arranging to get the stones from this collection.

Moe K.S., Johnson P., Pearce C. (2005) Lab Notes: Identification of turquoise with diffuse reflectance spectroscopy. $G \uplus G$, Vol. 41, No. 4, pp. 348-349.

Moe K.S., Moses T.M., Johnson P. (2007) Polymer-impregnated turquoise. $G \uplus G$, Vol. 43, No. 2, pp. 149-151.

Nassau K. (1994) Gemstone Enhancement: History, Science and State of the Art, 2nd ed. Butterworth-Heinemann, Oxford, UK.

O'Donoghue M. (2006) Gems, 6th ed. Butterworth-Heinemann, Oxford, UK.

Owens P.A., Eaton-Magaña S. (2009) Lab Notes: Eljen treated turquoise. $G \uplus G$, Vol. 45, No. 2, p. 140.

Rockwell K.M. (2008) Lab Notes: Composite of coral and plastic. Ge) G, Vol. 44, No. 3, p. 253.

Webster R. (1994) Gems: Their Sources, Descriptions and Identification, 5th ed. Revised by P. Read, ButterworthHeinemann, Oxford, UK.
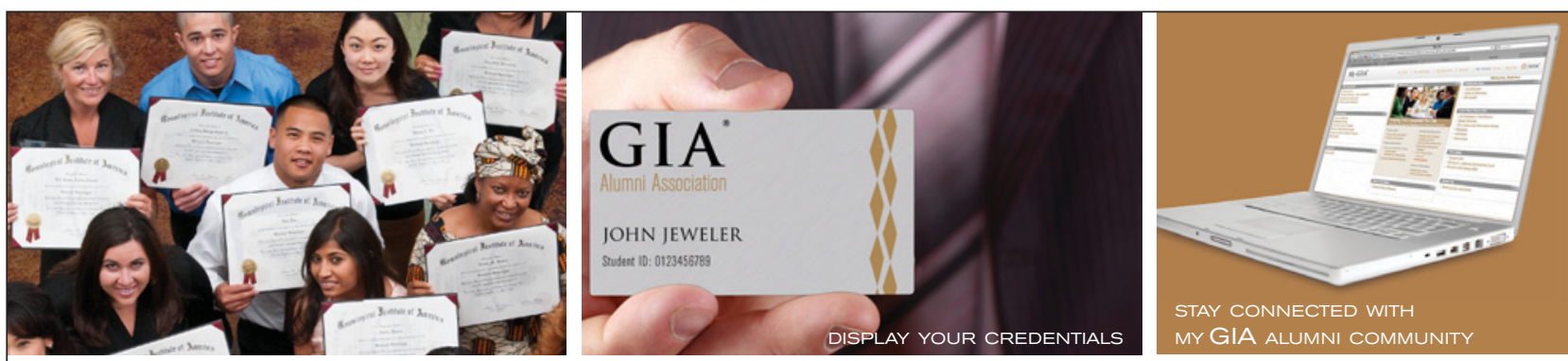

Your GIA diploma was just the beginning.

Introducing GIA's completely redesigned Continuing Education Program for Graduate Gemologists and Gemologists.

- Completing assignments in GIA's easy-to-use online learning environment is engaging and fun.

- Online discussions and live chats keep you connected with experts from all over the world.
- Access to all GIA eLearning gemology course materials keeps an entire gem and jewelry reference library right at your fingertips.

- Affordable \$189 annual fee, or bundle it with a G\&G online subscription for just $\$ 60$ more.

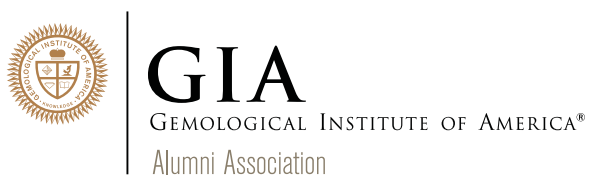

Visit unw. gia.edu for more information or to get started today. 